\title{
Comparison of the
} hemodynamic effects of sevoflurane anesthesia induction and maintenance vs TIVA in CABG surgery

\author{
Normand R. Gravel MD, \\ Norman R. Searle MDCM, \\ Jean Taillefer MD, \\ Michel Carrier MD, \\ Micheline Roy RRT, \\ Line Gagnon RRT
}

\begin{abstract}
Purpose: To compare the hemodynamic effects of sevoflurane when used for induction and maintenance of anesthesia with a total intravenous technique in patients with known coronary artery disease (CAD).

Methods: Thirty patients undergoing elective coronary artery bypass graft (CABG) were randomly allocated to receive either sevoflurane ( $S$ group, $n=15$ ) at a minimal concentration of $4 \%$ in oxygen for induction and at $0.5-2$ MAC end-tidal concentration for maintenance, or a total intravenous technique ( $T$ group, $n=15$ ) consisting of midazolam for induction and propofol for maintenance. In both groups, anesthesia was supplemented with sufentanil and muscle relaxation with cis-atracurium. Hemodynamic measurements included systemic and pulmonary pressures, heart rate, mixed venous oxygen saturation and cardiac output at the following times: pre-induction, 7 and 25 min post-induction, chest closure, one hour after surgery and pre and post tracheal extubation.

Results: More patients in the $S$ group (8/15) presented bradycardia in the induction period (T:2/15) $(P=0.05)$. During maintenance of anesthesia, treatment of hypertension was more frequent in the T group $(12 / 15)$ than in the $S$ group $(6 / 15)(P=0.025)$. All other parameters were comparable.

Conclusion: Induction of anesthesia in patients with CAD, VCRII with sevoflurane supplemented by sufentanil provided hemodynamic responses comparable with those of TIVA although bradycardia was observed more often with sevoflurane. Intraoperative control of systemic blood pressure was achieved with fewer interventions with a sevoflurane/sufentanil maintenance than with a propofol/sufentanil technique in CABG surgery.
\end{abstract}

Objectif : Comparer les effets hémodynamiques d'une anesthésie exclusivement intraveineuse (AEI) à une technique utilisant le sévoflurane durant la chirurgie de revascularisation myocardique.

Méthode : Trente patients programmés pour une chirurgie de revascularisation myocardique (PAC) ont été répartis de façon aléatoire pour recevoir soit du sévoflurane (groupe $S, n=15$ ) à une concentration minimale de $4 \%$ dans l'oxygène pour l'induction et à une concentration en fin d'expiration de 0.5-2 MAC pour le maintien, soit une technique TIVA (groupe $T, N=15$ ) comprenant du midazolam pour l'induction et du propofol pour le maintien. Dans les deux groupes, l'anesthésie était complétée avec du sufentanil et du cis-atracurium. Les mesures hémodynamiques comprenaient les pressions systémiques et pulmonaires, la fréquence cardiaque, la saturation en oxygène du sang veineux mêlé et le débit cardiaque aux moments suivants : pré-induction, 7 et 25 min post-induction, à la fermeture du sternum, une heure après la fin de la chirurgie, avant et après l'extubation.

Résultats : Plus de patients du groupe $S(8 / 15)$ vs groupe $T(2 / 15)$ ont présenté de la bradycardie durant linduction $(P=0,05)$. Durant le maintien, le traitement de l'hypertension a été plus fréquent dans le groupe $T(12 / 15)$ que dans le groupe $S(6 / 15)(P=0,025)$ pour contrôler la réponse hémodynamique $( \pm 20 \%$ valeurs de base). Tous les autres paramètres étaient comparables.

Conclusion : Pour l'induction de l'anesthésie chez des patients coronariens, l'induction VCRIl avec du sévoflurane, supplémentée avec du sufentanil, offre une réponse hémodynamique comparable à une technique AEI. Cependant une incidence de bradycardie est observée plus souvent avec la première. Lors de la chirurgie, le contrôle intraopératoire de la pression sanguine est obtenue avec moins d'intervention avec la technique sevoflurane/sufentanil.

From the Département d'Anesthésie, Institut de Cardiologie de Montréal, Université de Montréal, 5000 est rue Bélanger, Montréal, Québec HIT 1 C8 Canada.

Address correspondence to: Dr. Norman R Searle. Phone: 514-376-3330 Ext: 3732; Fax: 514-376-8784; E-mail: nsearle@total.net Accepted for publication December 13, 1998. 
$\mathrm{T}$

HE introduction of sevoflurane, owing to its low blood-gas solubility and minimal pungency, has led to a growing interest for inhaled induction of general anesthesia in adults. ${ }^{1-3}$ When used in high concentrations for rapid inhalational anesthesia in adults, it is well accepted by the majority of patients. ${ }^{4}$ Moreover, sevoflurane has been recently described as comparable to isoflurane in the maintenance of anesthesia in cardiac patients undergoing noncardiac surgery with respect to the incidence and severity of intra and postoperative myocardial ischemia and in the frequency of adverse cardiac outcomes. ${ }^{5}$ We believe it is important to evaluate and confirm the safety of sevoflurane for inhalational induction in patients with coronary artery disease (CAD).

The present study was designed to compare the hemodynamic effects of sevoflurane when used as the main induction and maintenance agent during coronary artery bypass graft (CABG) surgery compared with a standard total intravenous anesthesia technique (midazolam, propofol), both supplemented with lowdose sufentanil.

\section{Methods}

Participants

Following institutional review board approval, written informed consent was obtained from 30 patients (ASA 3-4) scheduled for elective CABG with or without cardiopulmonary bypass (CPB) but with sternotomy. Inclusion criteria were: age $>18$ and $<75 \mathrm{yr}$, left ventricular ejection fraction $>40 \%$, normal hepatic and renal function. Exclusion criteria were: emergency surgery, allergy to study medication, drug or alcohol abuse, gastro-esophegal reflux, obesity (body mass index $>32$ ), anticipated difficult intubation.

\section{Study design}

Randomisation was in blocks of six with sealed envelopes (3:3) to allocate recruited patients to either sevoflurane $(S)$ or to total intravenous anesthesia ( $T$ ) groups. The investigator was not aware of randomisation until the morning of surgery. The induction sequence was performed by the same anesthetist in all cases (NRG). Timesequence of induction-intubation period is detailed in Table I. A standard premedication consisting of $2 \mathrm{mg}$ lorazepam po and $0.15 \mathrm{mg} \cdot \mathrm{kg}^{-1}$ morphine sulfate im 60 $90 \mathrm{~min}$ before induction was administered on the ward together with the patients' usual cardiac medication. Patients receiving $i v$ nitroglycerine and/or heparin, on the morning of surgery, had their infusions stopped on arrival in the operating room (OR). All patients received $10 \mathrm{ml} \cdot \mathrm{kg}^{-1}$ lactated Ringer's iv before induction.

\section{Monitoring}

In the $\mathrm{OR}$, basic anesthetic monitors were installed, including: ECG monitoring of lead II and V5 with continuous ST-segment analysis and trending (Siemens Sirecust 1281, Danvers, MA), pulse oxymetry and non invasive blood pressure. Peripheral and central vascular catheters insertion e.g. 20-gauge radial artery catheter, a triple-lumen central and a thermodilution oxymetric pulmonary artery catheter (Oxymetrics $\mathrm{SVO}_{2} \mathrm{PAC}$; Opticath Abbott laboratories, North Chicago,Il) were placed under local anesthesia and supplemental intravenous sedation (1 mg midazolam and $0.05 \mathrm{mg} \cdot \mathrm{kg}^{-1}$ morphine sulfate). Respiratory gases were sampled from the filter distally to the Y-connector of the circle system into a multigas monitor (Datex Capnomac Ultima, Helsinki, Finland) to continuously monitor end-tidal (ET) and inspired concentrations of sevoflurane and carbon dioxide $\left(\mathrm{CO}_{2}\right)$.

\section{Induction of anesthesia}

In the $S$ group, anesthesia was induced using the vital capacity rapid inhalational induction (VCRII) technique with a minimum of sevoflurane $4 \%$ in oxygen. ${ }^{6,7}$ To offer uniform induction conditions and in order to prevent sevoflurane spills during handling of the breathing system, we interposed a bidirectional valve distally to the Y-piece. This valve allowed rapid transfer of the respiratory gas between the circle system and the patient.

A fresh gas flow $>6 \mathrm{~L} \cdot \mathrm{min}^{-1}$ was delivered by an Ohmeda (Sevotec 5) or a Penlon (Sigma) vaporizer into the circle system of an Ohmeda or Siemens anesthesia machine. After replacing the mask with a dynamic model lung (restrictive reservoir bag), the vaporizer was set to a high concentration $(>5 \%)$ and the respiratory gas was circulated in the system using the ventilator. The circle was primed until a concentration of sevoflurane $>4 \%$ was obtained as measured by the gas analyser. The circle system was returned to manual ventilation (with an open adjustable pressure limiting valve) and the mask was replaced. The patients breathed $\mathrm{O}_{2} 100 \%$ before induction of anesthesia. Before applying the mask to their faces, the patients were instructed to breathe out to residual volume; the mask was then applied, and the patients were instructed to breathe in deeply and to hold their breath for as long as it was comfortable. They were then asked to take deep breaths until loss of consciousness which was defined as absence of response to verbal command and the absence of eyelid reflex. Upon loss of consciousness, the sevoflurane vaporizer setting was reduced to $2 \%$. 
TABLE I Time-sequence of induction-intubation period

\begin{tabular}{ll}
\hline - 2 min following insertion of & \\
vascular catheters & Pre-induction (Pre-ind) \\
- Loss of consciousness & $\mathrm{T} 0$ min \\
- Administration of muscle relaxant & \\
and opioid bolus & $\mathrm{T} 0$ through $\mathrm{T}+2 \mathrm{~min}$ \\
- Oro-tracheal intubation & $\mathrm{T}+5$ min \\
- Post-intubation measurement & $\mathrm{T}+7$ min (Post-intub) \\
- Pre-incision measurement & $\mathrm{T}+25$ min \\
\hline
\end{tabular}

TABLE II Demographics data, preoperative status and medication, type of surgery. Mean \pm SD when appropriate.

\begin{tabular}{llll}
\hline & $\begin{array}{l}\text { Sgroup } \\
(n=15)\end{array}$ & $\begin{array}{l}\text { Tgroup } \\
(n=15)\end{array}$ & $P$ \\
\hline Age (yr) & $60 \pm 9$ & $63 \pm 9$ & NS \\
Weight (kg) & $70 \pm 13$ & $77 \pm 13$ & NS \\
Sex (M:F) & $10: 5$ & $11: 4$ & NS \\
ASA (III:IV) & $3: 12$ & $2: 13$ & NS \\
Hypertension (n) & $11(73 \%)^{*}$ & $10(67 \%)^{*}$ & NS \\
Diabetes (n) & $3(20 \%)^{*}$ & $3(20 \%)^{\star}$ & NS \\
Heparin preop (n) & $9(60 \%)^{*}$ & $9(60 \%)^{*}$ & NS \\
Beta-blockers (n) & $9(60 \%)^{\star}$ & $12(80 \%)^{\star}$ & NS \\
Calcium entry blockers (n) & $10(67 \%)^{\star}$ & $9(60 \%)^{\star}$ & NS \\
ACEI (n) & $4(27 \%)^{*}$ & $3(20 \%)^{\star}$ & NS \\
Distal grafts (n) & 2.9 & 2.9 & NS \\
Use of CPB (n) & 12 & 11 & NS \\
\hline
\end{tabular}

ASA - American Society of Anaesthesiologists; ACEI = angiotensin conversion enzyme inhibitor; $\mathrm{CPB}=$ cardiopulmonary bypass; " percentage of patients within group.

In the $T$ group, anesthesia was induced with $1 \mathrm{mg}$ midazolam iv q $15 \mathrm{sec}$ via a central line until loss of consciousness while patients breathed $\mathrm{O}_{2} 100 \%$.

Behavioural or airway incidents (excitation, movement, cough, laryngospasm, etc) during induction were noted. In both groups, following loss of consciousness, the lungs were manually ventilated by mask and a bolus of $0.15 \mathrm{mg} \cdot \mathrm{kg}^{-1}$ cisatracurium iv over $10 \mathrm{sec}$ followed by a bolus of $0.5 \mu \mathrm{g} \cdot \mathrm{kg}^{-1}$ sufentanil $i v$ over two minutes was administered. Orotracheal intubation was performed at $T+5 \mathrm{~min}$ in both groups. After intubation, controlled ventilation with a fresh gas flow $>2 \mathrm{~L} \cdot \mathrm{min}^{-1}$ was initiated and adjusted to maintain normocapnia (35-45 $\mathrm{mmHg} \mathrm{CO}_{2}$ ).

Anesthesia maintenance and bemodynamic interventions Anesthesia was maintained with sevoflurane 0.5-2 MAC ET concentration (S group) or with 40-150 $\mu \mathrm{g} \cdot \mathrm{kg}^{-1} \cdot \mathrm{min}^{-1}$ propofol ( $\mathrm{T}$ group) and adjusted to achieve hemodynamic stability within $\pm 20 \%$ of baseline values (average of the last three measurements on the ward). In both groups, infusions of $1.5-3 \mu \mathrm{g} \cdot \mathrm{kg}^{-1} \cdot \mathrm{min}^{-1}$ cis- atracurium and $0.5 \mu \mathrm{g} \cdot \mathrm{kg}^{-1} \cdot \mathrm{hr}^{-1}$ sufentanil were
TABLE III Use of anaesthetic and vasoactive drugs during and after surgery. Mean $\pm \mathrm{SD}$ when appropriate.

\begin{tabular}{llll}
\hline & $\begin{array}{l}\text { Sgroup } \\
(n=15)\end{array}$ & $\begin{array}{l}\text { Tgroup } \\
(n=15)\end{array}$ & $P$ \\
\hline Total sufentanil $\left(\mu \mathrm{g} \cdot \mathrm{kg}^{-1}\right)$ & $1.87 \pm 0.45$ & $1.72 \pm 0.21 \mathrm{NS}$ \\
Total cis-atracurium $\left(\mathrm{mg}^{-1} \cdot \mathrm{kg}^{-1}\right)$ & $0.46 \pm 0.19$ & $0.40 \pm 0.06 \mathrm{NS}$ \\
Total propofol $\left(\mathrm{mg} \cdot \mathrm{kg}^{-1}\right)$ & $\mathrm{NA}$ & $21.98 \pm 6$ & $\mathrm{NA}$ \\
NTG post-sternotomy $(\mathrm{n})$ & $6(40 \%)^{\star}$ & $12(80 \%)^{\star}$ & 0.025 \\
Dopamine $<5 \mu \mathrm{gg} \cdot \mathrm{kg}^{-1} \cdot \mathrm{min}^{-1}(\mathrm{n})$ & $2(13 \%)^{*}$ & $3(20 \%)^{*}$ & $\mathrm{NS}$ \\
Norepinephrine $<5 \mu \mathrm{g} \cdot \mathrm{min}^{-1}(\mathrm{n})$ & $2(13 \%)^{*}$ & $1(7 \%)^{*}$ & $\mathrm{NS}$ \\
Milrinone $50 \mu \mathrm{g} \cdot \mathrm{kg}^{-1} \cdot \mathrm{min}^{-1}(\mathrm{n})$ & $1(7 \%)^{*}$ & $1(7 \%)^{*}$ & $\mathrm{NS}$ \\
\hline
\end{tabular}

MAC = minimal alveolar concentration; NTG - nitroglycerine; $\mathrm{SBP}=$ systolic blood pressure; ${ }^{*}=$ percentage of patients within group.

TABLE IV Use of vasoactive drugs during induction

\begin{tabular}{llll}
\hline & $\begin{array}{l}S \text { group } \\
(n=15)\end{array}$ & $\begin{array}{l}\text { T group } \\
(n=15)\end{array}$ & $P$ \\
\hline Glycopyrrolate (n) & $\mathbf{8 ( 5 3 \% ) ^ { * }}$ & $2(13 \%)^{*}$ & 0.05 \\
Ephedrine-phenylephrine (n) & $6(40 \%)^{*}$ & $5(33 \%)^{*}$ & NS \\
NTG (n) & 0 & 0 & NS \\
Esmolol (n) & 0 & 0 & NS \\
\hline
\end{tabular}

NTG = nitroglycerine; * percentage of patients within group.

maintained until closure of the chest. If anesthetic adjustments (sevoflurane or propofol) failed in obtaining previously described hemodynamic values (" $20 \%$ baseline), a strict protocol was applied and the following drugs were administered: phenylephrine and/or ephedrine for hypotension, nitroglycerine for hypertension, glycopyrrolate for bradycardia and esmolol for tachycardia. Ischemia was treated with intravenous nitroglycerine. During CPB, in the $S$ group, sevoflurane was administered in a concentration of $1-2 \%$ via a Sevotec 5 vaporizer connected to the fresh gas flow canalisation proximal to the oxygenator, while in the $T$ group, propofol infusion was maintained between 120 and $150 \mu \mathrm{g} \cdot \mathrm{kg}^{-1} \cdot \mathrm{min}^{-1}$.

Postoperative analgesia was standardized, all patients received $100 \mathrm{mg}$ indomethacine $p r$ at the conclusion of surgery; on arrival in the ICU, a 2 $\mathrm{mg} \cdot \mathrm{hr}^{-1}$ morphine infusion was initiated and maintained until patients were breathing sponteanously (CPAP). Intensive care unit interventions (fluid management, transfusion therapy, inotropic support, etc) were as per standard institution protocols.

\section{Data collection}

Hemodynamic measurements included systemic and pulmonary artery pressures, $\mathrm{HR}$, central venous and pulmonary wedge pressures, mixed venous oxygen 
TABLE V Perioperative metabolic changes. Mean (SD).

\begin{tabular}{|c|c|c|c|c|c|c|c|}
\hline Variable & $\begin{array}{l}\text { Pre-induction } \\
\mathrm{S}: \mathrm{n}=14 \\
\mathrm{~T}: \mathrm{n}=15\end{array}$ & $\begin{array}{l}\text { Post-intubation } \\
\text { (T-7 min) } \\
S: \mathrm{n}=14\end{array}$ & $\begin{array}{l}T-25 \min \\
S: n=15 \\
T: n=15\end{array}$ & $\begin{array}{l}\text { Closure } \\
S: n=15 \\
T: n=15\end{array}$ & $\begin{array}{l}1 \mathrm{br} I C U \\
S: \mathrm{n}=14 \\
\mathrm{~T}: \mathrm{n}=15\end{array}$ & $\begin{array}{l}C P A P \\
\mathrm{~S}: \mathrm{n}=14 \\
\mathrm{~T}: \mathrm{n}=15\end{array}$ & $\begin{array}{l}1 \text { br post- extubation } \\
S: n=13 \\
T: n=15\end{array}$ \\
\hline $\mathrm{O}_{2}$ & $\begin{array}{l}\mathrm{S}: 449(94) \\
\mathrm{T}: 470(97)\end{array}$ & $\begin{array}{l}\mathrm{S}: 384(135) \\
\mathrm{T}: 395(99)\end{array}$ & $\begin{array}{l}S: 365(97) \\
T: 342(80)\end{array}$ & $\begin{array}{l}S: 333(68) \\
T: 320(83)\end{array}$ & $\begin{array}{l}S: 461(122) \\
T: 399(99)\end{array}$ & $\begin{array}{l}S: 407(98) \\
T: 424(102)\end{array}$ & $\begin{array}{l}S: 419(94) \\
T: 441(121)\end{array}$ \\
\hline $\begin{array}{l}\mathrm{VO}_{2} \\
\mathrm{~mL} \cdot \mathrm{min}^{-1} \cdot \mathrm{m}^{-2}\end{array}$ & $\begin{array}{l}S: 93(16) \\
T: 99(16)\end{array}$ & $\begin{array}{l}S: 74(11) \\
T: 76(12)\end{array}$ & $\begin{array}{l}S: 65(10) \\
T: 64(12)\end{array}$ & $\begin{array}{l}S: 82(15) \\
T: 81(14)\end{array}$ & $\begin{array}{l}S: 133(33) \\
T: 119(25)\end{array}$ & $\begin{array}{l}S: 115(26) \\
T: 121(17)\end{array}$ & $\begin{array}{l}S: 118(25) \\
T: 120(29)\end{array}$ \\
\hline
\end{tabular}

$\mathrm{DO}_{2}=$ oxygen delivery $; \mathrm{VO}_{2}=$ oxygen consumption; $\mathrm{O}_{2} \mathrm{ER}=$ oxygen extraction ratio $\mathrm{CPAP}=$ continuous positive airway pressure.

saturation $\left(\mathrm{SvO}_{2}\right)$ and triplicate determination of cardiac output $(\mathrm{CO})$ at the following times: Pre-induction (Pre-ind), $\mathrm{T}+7 \mathrm{~min}$ (Post-intub), $\mathrm{T}+25 \mathrm{~min}$, at beginning of chest closure (Closure), one hour after the arrival in ICU (one hour ICU), when patients were breathing sponteanously (CPAP) and one hour after extubation (Post-extub). At the same time as these measurements, blood was drawn from the radial and pulmonary artery lines for $\mathrm{Hb}-\mathrm{Hct}$ and for blood gas analysis (co-oxymetry) for determination of oxygen delivery $\left(\mathrm{DO}_{2}\right)$ and consumption $\left(\mathrm{VO}_{2}\right)$ determinations. Oxygen extraction ratio $\left(\mathrm{O}_{2} \mathrm{ER}\right)$ was calculated according to the following formula:

$$
\mathrm{O}_{2} \mathrm{ER}=\mathrm{CaO}_{2}-\mathrm{CvO}_{2} / \mathrm{CaO}_{2}
$$

Charts from all patients were reviewed for incidence of postop CK-MB elevation, new myocardial infarction on ECG, elevation of creatinine and duration of hospitalisation.

\section{Statistical analysis}

Data were analysed using chi-square test for nominal variables. Two-way (time treatment) repeated measures mixed model ANOVA was used to test differences between groups regarding the evolution across time of continuous variables, such as heart rate, systolic blood pressure and diastolic blood pressures. When time treatment interaction was significant, slice effects were analyzed, i.e. time effect was analyzed for each level of treatment and treatment effect was analyzed for each level of time. To keep the overall level of significance at $\mathbf{5 \%}$, levels of significance for testing simple effects were adjusted according to the Bonferroni rule. These analyses were performed with the mixed procedure of SAS7 6.12. A $P$ value $<0.05$ was considered significant.

\section{Results}

The groups were demographically similar with no differences in terms of age, weight, height or sex.
Distribution of patients was similar in regard to the following characteristics: ASA status, hypertension, diabetes, preop iv heparin, cardiac medication, type of surgery (number of distal grafts) and use of CPB (Table II). Mean baseline (ward) SBP was numerically higher in the $\mathrm{T}$ group than in the $\mathrm{S}$ group ( $\mathrm{T}: 132 \pm$ 14 vs S: $123 \pm 12 \mathrm{mmHg}$ ) although not statistically significant $(P=0.09)$. The remaining baseline values ( $\mathrm{HR}, \mathrm{SvO}_{2}, \mathrm{CI}$ ) were comparable. No incidents (coughing, laryngospasm, movement) were observed in relation to the VCRII technique. The $\mathrm{T}$ patients received an average of $0.11 \pm 0.05 \mathrm{mg} \cdot \mathrm{kg}^{-1}$ midazolam for induction. In the $S$ group, the mean MAC ET concentration of sevoflurane at $\mathrm{T}+7$ and $\mathrm{T}+25 \mathrm{~min}$ was $0.6 \pm 0.08 \mathrm{MAC}$. The total doses of sufentanil and cis-atracurium were comparable between groups (Table III).

In both groups, during the induction period (Postintub to $\mathrm{T}+25 \mathrm{~min}$ ), there were decreases in $\mathrm{HR}$, SBP and cardiac index (CI) compared with the pre-induction values (Figures 1-3). During the same period there was an increase in $\mathrm{SvO}_{2}$ (Figure 4). The incidence of hypotension during induction was similar in both groups (S: $40 \%$ vs T: $33 \%$ ) (Table IV). Bradycardia was observed more frequently in the $S$ group than in the $\mathrm{T}$ group ( $\mathrm{S}: 8$ ps T:2 pts, $P=0.05$ ) but, apart from glycopyrrolate, the use of vasoactive drugs during induction was similar (Table IV). No patients presented tachycardia and no ischemic events were identified during the induction-intubation period.

Throughout data collection, values of $\mathrm{HR}, \mathrm{SBP}, \mathrm{CI}$, $\mathrm{SvO}_{2}$ (Figures l-4), $\mathrm{DO}_{2}, \mathrm{VO}_{2}$ and $\mathrm{O}_{2} \mathrm{ER}$ (Table V) did not differ between groups (repeated measure mixed model ANOVA $P>0.05$ ) except at post-intub for SBP (S: $104 \pm 11$ vs $120 \pm 19 \mathrm{mmHg}, P=0.003$ ). However, the change in SBP ( $\Delta$ pre-ind ps post-intub) was not significant $(P=0.17)$. Thus the magnitude of $S B P$ reduction during induction was comparable in both groups. During sternotomy, more patients in the $T$ group $(12 / 15 \mathrm{pts})$ than in the $S$ group $(6 / 15)$ 


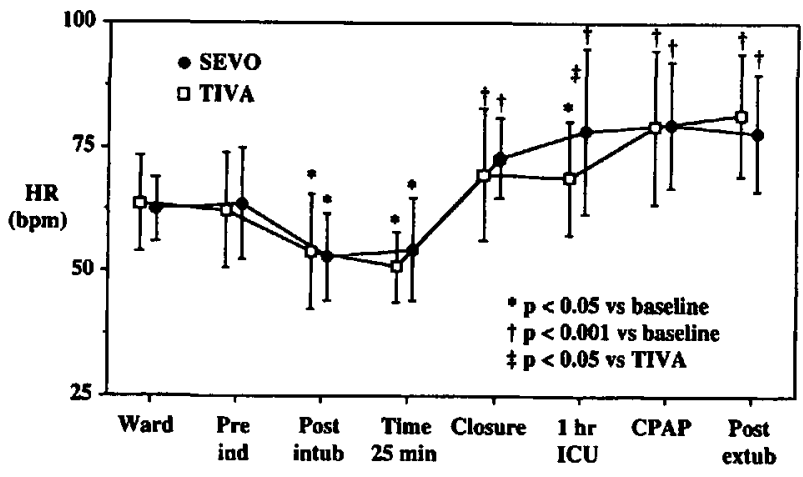

FIGURE 1 Mean perioperative heart rate (HR) for sevoflurane (SEVO) and total intravenous (TIVA) groups at baseline (Ward), pre-induction (Pre-ind), post-intubation (Post-intub), $25 \mathrm{~min}$ after induction (Time $25 \mathrm{~min}$ ), sternum closure (Closure), one hour after arrival in intensive care unit (one hour ICU), prior to extubation when on continuous positive airway pressure (CPAP) and one hour after extubation (Post-extub).

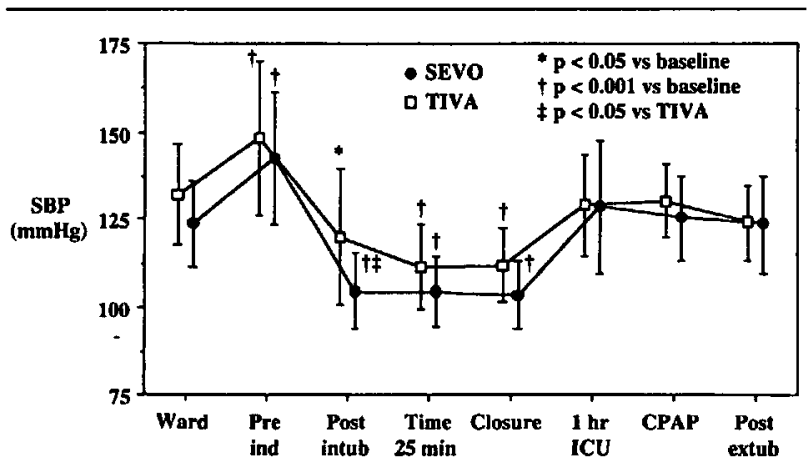

FIGURE 2 Mean perioperative systolic blood pressure (SBP) for sevoflurane (SEVO) and total intravenous (TIVA) groups at baseline (Ward), pre-induction (Pre-ind), post-intubation (Post-intub), $\mathbf{2 5}$ min after induction (Time $25 \mathrm{~min}$ ), sternum closure (Closure), one hour after arrival in intensive care unit (one hour ICU), prior to extubation when on continuous positive airway pressure (CPAP) and one hour after extubation (Post-extub).

required pharmacological intervention (NTG) to control SBP $(P=0.025)$ (Table IV).

Two patients in the $T$ group presented excessive postoperative bleeding and were excluded from early extubation. Time to extubation $(n=28)$ was similar (S: $210 \pm 66$ vs $\mathrm{T}: 208 \pm 76 \mathrm{~min}$ ) and no reintubation was necessary. Use of inotropic agents at the conclusion of surgery was similar in both groups (Table III); the intra-aortic balloon pump was never needed. No patient suffered perioperative MI or renal failure although two patients in the $\mathrm{T}$ group showed tran-

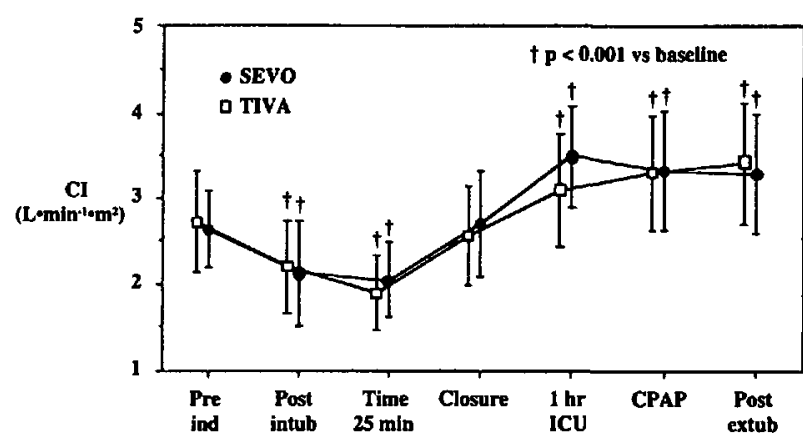

FIGURE 3 Mean perioperative cardiac index (CI) for sevoflurane (SEVO) and total intravenous (TIVA) groups at baseline-preinduction (Pre-ind), post-intubation (Post-intub), $25 \mathrm{~min}$ after induction (Time $25 \mathrm{~min}$ ), sternum closure (Closure), one hour after arrival in intensive care unit (one hour ICU), prior to extubation when on continuous positive airway pressure (CPAP) and one hour after extubation (Post-extub).

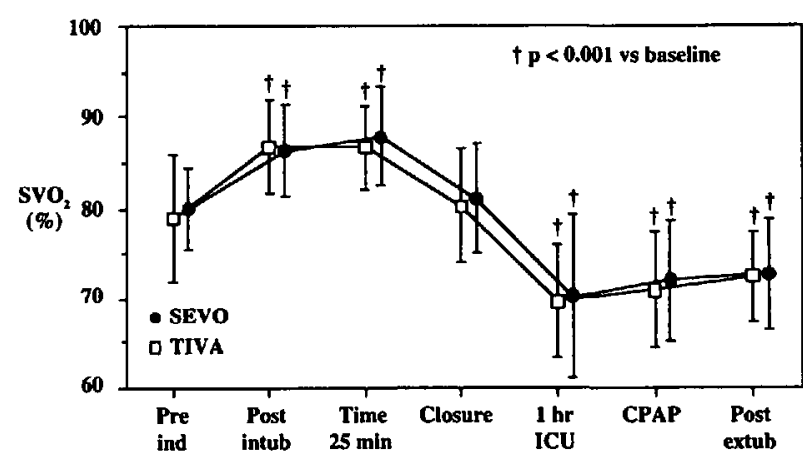

FIGURE 4 Mean perioperative mixed venous oxygen saturation $\left(\mathrm{SvO}_{2}\right)$ for sevoflurane (SEVO) and total intravenous (TIVA) groups at baseline-pre-induction (Pre-ind), post-intubation (Postintub), $25 \mathrm{~min}$ after induction (Time $25 \mathrm{~min}$ ), sternum closure (Closure), one hour after arrival in intensive care unit (one hour ICU), prior to extubation when on continuous positive airway pressure (CPAP) and one hour after extubation (Post-extub.)

sient elevation of serum creatinine. No death occurred and the average hospital stay after surgery was five days (S: $5.3 \pm 1$ ps T: $5.1 \pm 1.9$ days).

\section{Discussion}

Our results suggest that sevoflurane supplemented with low-dose sufentanil provides hemodynamic control during the induction-intubation period comparable to that of a total intravenous technique (midazolam - lowdose sufentanil - propofol) for patients undergoing elective CABG surgery. Inhalational induction of anes- 
thesia has regained popularity with the introduction of a low-solubility and non-irritating volatile agent. Several studies, in pediatric and adult settings, has compared efficacy, tolerability and rapidity of different halogeneted agents to induce anesthesia with a single breath technique in ASA I and II patients. In this study, we submitted ASA III and IV patients to rapid inhalational induction with a minimum of $4 \%$ sevoflurane. Although we did not assess the precise time to loss of consciousness, all the $S$ patients were rapidly unresponsive to stimulation within one minute of beginning the induction and remained free of excitation, movement or airway-related incidents. This is most likely related to the effect of the premedication and supplemental sedation given to all patients prior to insertion of invasive monitoring. Small doses of $i v$ sedatives given before an inhalational induction with sevoflurane improve the speed and quality of the induction. ${ }^{8}$ Thus, induction was smooth and well tolerated by all the $S$ patients.

In both groups, following induction of anesthesia, there was a comparable reduction in $\mathrm{CI}$ and increase in $\mathrm{SvO}_{2}$ secondary to a decrease in $\mathrm{O}_{2}$ consumption and extraction. In the postoperative period, although the $\mathrm{CI}$ values were higher than baseline values, the $\mathrm{SvO}_{2}$ remained lower than preoperative values secondary to an increase in $\mathrm{O}_{2}$ consumption and extraction. These results are consistent with reports that there is no correlation between $\mathrm{SvO}_{2}$ and $\mathrm{CI}$ when the latter is $>2 \mathrm{~L} \cdot \mathrm{min}^{-1} \cdot \mathrm{m}^{-2} \cdot 9,10$

When corrected for the difference between groups at baseline, the variance in pre-induction and postintubation SBP was not statistically significant. Moreover, the average value of $104 \mathrm{mmHg}$ for SBP post-intub, in the $S$ group, is clinically acceptable and suggests that these patients may have been at a deeper level of anesthesia than those in the $\mathrm{T}$ group (mean SBP post-intub: $120 \mathrm{mmHg}$ ). Although $\mathrm{HR}$ values were comparable during data collection in the periinduction period (Figure 1), more patients in the $S$ group needed glycopyrrolate for $\mathrm{HR}<80 \%$ of baseline between T0 and T+25 min (Table IV). These episodes varied from sinus bradycardia to nodal rythm, were transient, and non consequential. Sevoflurane has already been shown to provide consistently lower heart rates values during the early maintenance period and after surgical incision when compared with other halogeneted agents. ${ }^{11-13}$ Our results suggests that this property of sevoflurane may be enhanced by the combination sufentanil/cis-atracurium.

The incidence of hypotensive events (SBP $<80 \%$ baseline) during induction (until T-25 min) was comparable in both groups. During the same period, there was no hypertension or tachycardia in either group.
This may be related to the combined effect of premedication, ip sedation prior to invasive monitoring and high preoperative use of beta-blockers $(70 \%)$. The fact that sevoflurane provides slower heart rates and lacks potent coronary vasodilating properties which are necessary to cause coronary steal, ${ }^{14,15}$ renders sevoflurane attractive as an induction agent for patients with $\mathrm{CAD}$.

During sternotomy, although propofol was administered in sufficient dosage to insure adequate anesthesia for surgery, the majority of patients in the $\mathrm{T}$ group needed NTG to control SBP. This is consistent with a previous report that supplementation of anesthesia for CABG surgery with volatile agents is associated with better control of blood pressure. ${ }^{16}$

Cardiac outcome was uneventful in all patients. No perioperative MI was detected. Patients' tracheas were extubated early in an average time of $209 \mathrm{~min}$. Following surgery, the $\mathrm{SvO}_{2}$ values remained stable, in both groups, despite the rapid weaning of ventilatory support and the early extubation.

\section{Limitations of the present study}

Because no monitoring of the depth of anesthesia was applied, equivalence of the two anesthetic techniques, particularly during induction, cannot be confirmed. No data are available to prove that the ceiling dose of propofol $\left(150 \mu \mathrm{g} \cdot \mathrm{kg}^{-1} \cdot \mathrm{min}^{-1}\right)$ and the maximal concentration of sevoflurane ( $2 \mathrm{MAC}$ ) used in this study are comparable. The impossibility of blinding the observer to treatment group (single-blind study) is also an inherent limitation.

\section{Conclusion}

This study demonstrates that sevoflurane supplemented with low-dose sufentanil has no deleterious hemodynamic effects when used as the main induction and maintenance agent in patients undergoing CABG surgery. Vital capacity rapid inhalational induction with high concentrations of sevoflurane offers a smooth technique and may be an alternative for induction of premedicated patients with known or suspected $C A D$. Compared with a total intravenous technique, the sevoflurane-sufentanil based anesthetic technique offers better control of systemic blood pressure during maintenance in CABG surgery but a higher incidence of bradycardia might be expected during induction.

\section{References}

1 Sloan MH, Conard PF, Karsunky PK, Gross JB. Sevoflurane versus isoflurane: induction and recovery characteristics with single-breath inhaled inductions of anesthesia. Anesth Analg 1996; 82: 528-32. 
2 Muzi M, Robinson BJ, Ebert TJ, $O=B$ rien TJ. Induction of anesthesia and tracheal intubation with sevoflurane in adults. Anesthesiology 1996; 85: 536-43.

3 Goresky GV, Muir J. Inhalational induction of anaesthesia (Editorial). Can J Anaesth 1996; 43: 1085-9.

4 McGinley J, Briggs $L$, Carey $M$. Inhalational induction with sevoflurane (Letter). Can J Anaesth 1997; 44: 1218.

5 Ebert TJ, Kharasch ED, Rooke GA, Shroff A, Muzi M, and the Sevoflurane Ischemia Study Group. Myocardial ischaemia and adverse cardiac outcomes in cardiac patients undergoing noncardiac surgery with sevoflurane and isoflurane. Anesth Analg 1997; 85: 993-9.

6 Yurino $M$, Kimura $H$. Efficient Inspired concentration of sevoflurane for vital capacity rapid inhalational induction (VCRII) technique. J Clin Anesth 1995; 7 : 228-31.

7 Turino $M$, Kimura $H$. A comparison of vital capacity breath and tidal breathing techniques for induction of anaesthesia with high sevoflurane concentrations in nitrous oxide and oxygen. Anaesthesia 1995; 50: 308-11.

8 Muzi M, Colinco MD, Robinson BJ, Ebert TJ. The effects of premedication on inhaled induction of anesthesia with sevoflurane. Anesth Analg 1997; 85: 1143-8.

9 Routsi C, Vincent J-L, Bakker J, et al. Relation between oxygen consumption and oxygen delivery in patients after cardiac surgery. Anesth Analg 1993; 77: 1104-10.

10 Magilligan DJ Jr, Teasdall $R$, Eisinminger $R$, Peterson $E$. Mixed venous oxygen saturation as a predictor of cardiac output in the postoperative cardiac surgical patient. Ann Thorac Surg 1987; 44: 260-2.

11 Fredman B, Nathanson $M H$, Smith I, Wang J, Klein $K$, White PF. Sevoflurane for outpatient anesthesia: a comparison with propofol. Anesth Analg 1995; 81: 823-8.

12 Frink EJ Jr, Malan TP, Atlas $M$, Dominguez LM, DiNardo JA, Brown BR Jr. Clinical comparison of sevoflurane and isoflurane in healthy patients. Anesth Analg 1992; 74: 241-5.

13 Ebert TJ, Muzi M, Lopatka CW. Neurocirculatory responses to sevoflurane in humans. Anesthesiology $1995 ; 83: 88-95$.

14 Kersten JR, Brayer AP, Pagel PS, Tessmer JP, Warltier $D C$. Perfusion of ischemic myocardium during anesthesia with sevoflurane. Anesthesiology 1994; 81: 995-1004.

15 Ebert TJ, Harkin CP, Muzi M. Cardiovascular responses to sevoflurane: a review. Anesth Analg 1995; 81: S11-22.

16 Ramsay JG, DeLima LGR, Wynands JE, O'Connor JP, Ralley $F E$, Robbins GR. Pure opioid versus opioidvolatile anesthesia for coronary artery bypass graft surgery: a prospective, randomized,double-blind study. Anesth Analg 1994; 78: 867-75. 